Delft University of Technology

\title{
Effect of bio-oil on low-intermediate temperature properties of organosolv lignin-bitumen
}

Zhang, Y.; Liu, X.; Ren, S.; Jing, R.; Gard, W.; Apostolidis, P.; Erkens, S.; Skarpas, A.

DOI

10.1201/9781003156222-05

Publication date

2021

Document Version

Accepted author manuscript

Published in

Functional Pavements - Proceedings of the 6th Chinese-European Workshop on Functional Pavement

Design, CEW 2020

\section{Citation (APA)}

Zhang, Y., Liu, X., Ren, S., Jing, R., Gard, W., Apostolidis, P., Erkens, S., \& Skarpas, A. (2021). Effect of bio-oil on low-intermediate temperature properties of organosolv lignin-bitumen. In X. Chen, J. Yang, M. Oeser, \& H. Wang (Eds.), Functional Pavements - Proceedings of the 6th Chinese-European Workshop on Functional Pavement Design, CEW 2020 (pp. 26-30). (Functional Pavements - Proceedings of the 6th Chinese-European Workshop on Functional Pavement Design, CEW 2020). CRC Press / Balkema - Taylor \& Francis Group. https://doi.org/10.1201/9781003156222-05

\section{Important note}

To cite this publication, please use the final published version (if applicable).

Please check the document version above.

\section{Copyright}

Other than for strictly personal use, it is not permitted to download, forward or distribute the text or part of it, without the consent of the author(s) and/or copyright holder(s), unless the work is under an open content license such as Creative Commons.

Takedown policy

Please contact us and provide details if you believe this document breaches copyrights.

We will remove access to the work immediately and investigate your claim. 


\title{
Effect of Bio-oil on Low-Intermediate Temperature Properties of Organosolv Lignin-Bitumen
}

\author{
Y. Zhang ${ }^{1,2}$, X. Liu ${ }^{1}$, S. Ren ${ }^{1}$, R. Jing ${ }^{1}$, W. Gard ${ }^{1}$, P. Apostolidis ${ }^{1}$, S. Erkens ${ }^{1}$, and A. \\ Skarpas ${ }^{1,3}$ \\ 1. Section of Pavement Engineering, Delft University of Technology, Delft, the Netherlands. \\ 2. School of Highway, Chang'an University, Xi'an, China. \\ 3. Department of Civil Infrastructure and Environmental Engineering, Khalifa University of Science and \\ Technology, Abu Dhabi, United Arab Emirates.
}

\begin{abstract}
Lignin, one of the most abundant natural polymers, has been extensively studied as liquid or solid additive in bituminous binders. Despite the fact the organosolv lignin in bitumen improves the overall resistance against oxidative aging, lignin could lead to binders of high thermal cracking sensitivity. In this study, a bio-based oil is implemented in a lignin modified bitumen to ameliorate characteristics, such as fatigue and thermal cracking resistance. Pressure aging vessel conditioning was applied to new binders formulated by different proportions of bio-oil to simulate the long-term aging. A series of rheological tests were performed. Based on the linear amplitude sweep test results, fatigue damage of lignin-bitumen could be reduced by increasing the oil content. According to relaxation test results, the addition of oil significantly decreased the ratio of residual stress and relaxation time. This study has shown preliminary conclusions on the use of bio-oil to improve the low-intermediate temperature performance of lignin-bitumen binders.
\end{abstract}

\section{INTRODUCTION}

Bitumen is a complex petroleum-based material that is the most widely used binder for paving applications. However, considering the uncertainty in crude oil supply, alternative binders are encouraged to be used as a replacement of bituminous binders or bitumen modifiers. Especially, lignin, among others, has attracted considerable attention as a modifier (Xu et al., 2017, Su et al., 2018) or substitute (van Vliet et al., 2016) of bitumen. Lignin is one of the most abundant natural polymers on Earth, with the total amount of lignin present in the biosphere estimated to exceed 300 billion tons and with an annual increase of approximately 20 billion tons (Bruijnincx, 2016). Lignin can be found as well in co-products of timber production, or byproducts of paper and pulp industries. Thus, the utilization of lignin in binders specially designed for pavements may bring large economic benefits to sustainable development.

The addition of lignin can indeed improve the performance of bitumen (Batista et al., 2018) and play a pivotal role as partial replacement of bitumen (Arafat et al., 2019). Meanwhile, the results have proved that lignin in bitumen could lead to enhanced thermal cracking sensitivity (Zhang et al., 2019, Norgbey et al., 2020). In this study, bio-based oil is implemented in lignin modified bituminous binders, or called lignin-bitumen, to improve the low-intermediate temperature performance. Dynamic Shear Rheometer (DSR) was used to implement a series of tests to evaluate the improvement of bio-oil in lignin-bitumen. Linear Amplitude Sweep (LAS) tests were used to characterize the fatigue behavior of new binders. Relaxation tests were conducted to evaluate relaxation properties as well.

\section{MATERIALS AND METHODS}

\subsection{Material preparation}

The virgin binder which was used in this research was a 70/100 pen grade bitumen of $47.5^{\circ} \mathrm{C}$ softening point. The pure lignin was a kind of nutbrown powder provided by the Chemical Point UG (Germany). Lignin particles with purity over $87 \%$ are extracted by organosolv methods. Helium Pycnometer Test was used to accurately measure the density of lignin was $1.3774 \mathrm{~g} / \mathrm{cm}^{3}$. The surface measuring system (Dynamic Vapor Sorption) was used to calculate the specific surface area of lignin by Braunauer-Emmett-Teller (BET) method was $147.0593 \mathrm{~m}^{2} / \mathrm{g}$. The physical 
parameters of lignin were tested after aging as well. The apparent color of lignin particles became darker, the density was increased to $1.5029 \mathrm{~g} / \mathrm{cm}^{3}$ and the specific surface area was decreased to $65.0475 \mathrm{~m}^{2} / \mathrm{g}$ (Zhang et al., 2020). Lignin particles became more compact with a smaller specific surface area after aging. The bio-oil used in this study was one of the most common rapeseed oil with saturated, monounsaturated, and polyunsaturated fatty acids.

The effect of different contents of lignin on bitumen had been studied. Here, the neat bitumen was the reference group, the lignin content by mass of bitumen was $30 \%$, the contents of bio-oil were 2,3 , and $4 \%$ by mass of lignin-bitumen, the label was Bref, BL30, BL30+2, 3, and 4\%, respectively. The lignin and bio-oil were added in the bitumen gradually. After premixing, the materials were mixed at a temperature of $163^{\circ} \mathrm{C}$ and a rate of $3000 \mathrm{rpm}$ by the high shear mixer. Thirty minutes was the mixing time to ensure that the materials are fully mixed. The Pressure Aging Vessel (PAV) device was simulated to the long-term aging process according to the standard testing procedure (ASTM D 6521-19). It was performed after the short-term aging procedure. A bitumen film with 3.2-mm thickness was formed by pouring $50 \pm 0.5 \mathrm{~g}$ materials into a standard 140-mm diameter PAV pan. Then the pans were placed in the PAV device at a temperature of $100^{\circ} \mathrm{C}$ under pressurized air at 2.10 MPa for 20 hours.

\subsection{Experimental methods}

\subsubsection{Linear Amplitude Sweep}

According to the standard testing procedure (AASHTO TP 101-14), a cyclic loading with linearly increasing strain amplitudes was used in the LAS test to assess the fatigue behavior of different binders. The 8-mm-diameter parallel plates with a 2-mm gap were used in LAS tests. The LAS test consisted of two steps; in the first step, the rheological properties of the sample were tested using a frequency sweep test at $20^{\circ} \mathrm{C}$ (applied load of $0.1 \%$ strain over a range of frequencies from $0.2-30 \mathrm{~Hz})$. Afterward, the samples were tested by applying a strain sweep $(10 \mathrm{~Hz})$.

\subsubsection{Relaxation test}

The stress relaxation demonstrates the ability of a material to relieve stress under a constant strain. The relaxation tests were performed in a DSR by using a parallel-plate configuration of 8-mm diameter and a 2-mm gap under strain-controlled mode at $0^{\circ} \mathrm{C}$. The tests were conducted as follows: firstly, the strain was increased from 0 to $1 \%$ shear strain in $0.1 \mathrm{~s}$, and then the $1 \%$ shear strain was kept constant during a relaxation period of $100 \mathrm{~s}$, while the change of shear stress was measured. Longer relaxation times imply that materials are more susceptible to stress accumulation. The relaxation time should be small enough to prevent high-stress accumulation in the asphalt pavement, caused by the continuous traffic load.

\section{RESULTS AND DISCUSSION}

\subsection{Linear Amplitude Sweep}

The LAS tests were used to measure the fatigue performance of lignin-bitumen. The number of cycles to failure (Nf) of different lignin modified bitumen at two typical applied shear strain levels, 2.5 and 5.0\%, were illustrated in Table 1. Obviously, the dramatic decrease in fatigue life was associated with an increase in strain level.

Fatigue life decreased with the addition of lignin at both high and low strain levels ( $2.5 \& 5.0 \%)$ by comparing the samples Bref and BL30. For fresh samples, the fatigue life of the BL30 was 24 and $23 \%$ of the Bref, under the applied strain level 2.5 and 5\%, respectively. After the aging process, the fatigue life of lignin-bitumen became 61 and $45 \%$ of the neat binder. The lignin led to stiffer binders, and subsequently these binders have shown increased resistance to deformation at high temperature. However, it may be prone to brittle fracture, which affects the low-intermediate temperature performance, an observation consistent with the conclusions of previous studies. Even if the lignin and bitumen were mixed uniformly, vulnerable interfaces between these two materials still exist, making them more susceptible to damage under accumulated loads.

To reduce the hardening effect of lignin on bitumen and damage to fatigue performance, oil was added to the binder. Fatigue life gradually increased to 42,55 , and $68 \%$ of the virgin binder at 2.5 strain level and 50,66, and $90 \%$ at 5.0 strain level with the increasing of oil. The 
improvement after aging was more obvious, but it was still lower than the neat bitumen. Oil could make the material softer, significantly improving and reducing the damage of lignin to fatigue performance.

Table 1. The fatigue life at the different applied strain of lignin-bitumen systems.

\begin{tabular}{ccccccc}
\hline Samples & & Bref & BL30 & BL30+2\% & BL30+3\% & BL30+4\% \\
\hline \multirow{2}{*}{$N_{f}(2.5 \%)$} & fresh & 1335 & 321 & 565 & 728 & 905 \\
& PAV & 1744 & 1057 & 1225 & 1300 & 1407 \\
\multirow{2}{*}{ Ratio (versus Bref) [\%] } & fresh & - & $24.0 \%$ & $42.3 \%$ & $54.5 \%$ & $67.8 \%$ \\
& PAV & - & $60.6 \%$ & $70.2 \%$ & $74.5 \%$ & $80.7 \%$ \\
$N_{f}(5.0 \%)$ & fresh & 203 & 47 & 102 & 133 & 183 \\
& PAV & 94 & 43 & 61 & 71 & 92 \\
\multirow{2}{*}{ Ratio (versus Bref) [\%] } & fresh & - & $23.2 \%$ & $50.3 \%$ & $65.5 \%$ & $90.2 \%$ \\
& PAV & - & $45.7 \%$ & $64.9 \%$ & $75.5 \%$ & $97.9 \%$ \\
\hline
\end{tabular}

\subsection{Relaxation Test}

The ratio of residual and initial shear stresses of samples before and after aging were shown in Figure 1. This indicator represented the residual stress after the end of a relaxation test. The larger the ratio, the more residual stress, the worse the recoverability, and vice versa. The fresh specimens have shown better elasticity and recoverability than aged samples with a lower ratio, properties deteriorate with aging. The residual stress of the aged samples was more than the fresh after one load. Then under repeated loading, the real traffic vehicle loads, the more residual accumulated stress would not be released and recovered. The addition of lignin increased the stress ratio increased the ratio both in fresh and aged states by comparing Bref and BL30. It shows that lignin is detrimental to relaxation properties. As the oil was added proportionally, this damaging effect was eliminated. The ratio of lignin-bitumen with bio-oil was even smaller than the neat binder. In addition to the ratio, the speed and time of relaxation also needed to be analyzed. The relaxation time as the shear stress was reduced to $50 \%$ and $25 \%$ of the initial stress is shown in Figure 1.

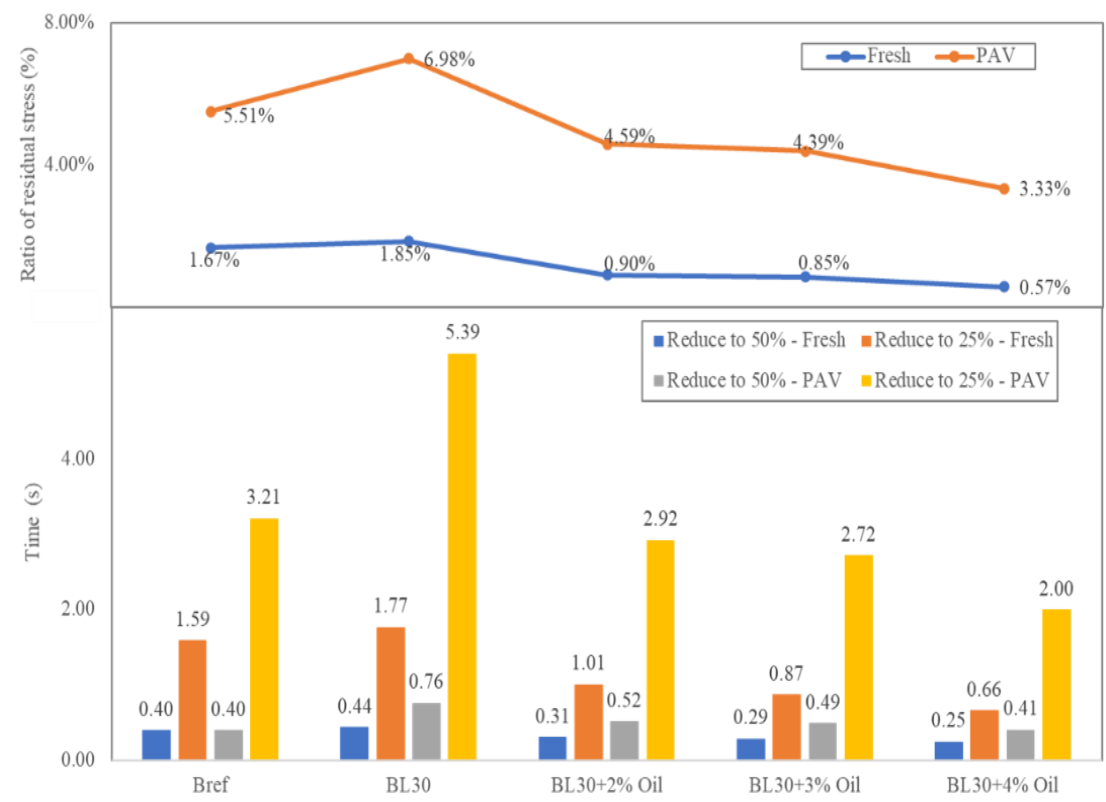

Figure 1. The ratio of stress and relaxation time of lignin-bitumen systems.

The index represented the time required for the stress to decrease to $50 \%$ and $25 \%$ of the initial stress $(0.1 \mathrm{~s})$. The longer it took for the stress to decrease to a certain stress level, the worse the recoverability. Longer relaxation times revealed that samples are more susceptible to stress accumulation (Jing, 2019). The relaxation time of all samples increased with the aging, it was consistent with the real situation. By comparing Bref and BL30, the relaxation times of the stress 
reduction to $50 \%$ and $25 \%$ increased with the addition of lignin. Lignin prolonged the time that the stress decreases to a certain level, which had a negative effect on the relaxation properties. The results were consistent with the analysis of residual stress ratio. However, the addition of oil significantly declined the relaxation time and improved the situation. The lignin modified bitumen with oil even needed less time than the neat bitumen, it showed improved relaxation performance.

\section{CONCLUSION}

Organosolv lignin significantly improved the modulus and high temperature stability of bitumen, played a role in partly replacing bitumen, and had certain damage to the intermediate and low temperature performance at the same time. The research presented in this study had shown the preliminary conclusions on the use of a bio-oil in lignin-bitumen.

According to the result of the linear amplitude sweep tests, the addition of lignin and the aging process significantly declined the fatigue life at both the stress level of $2.5 \%$ and $5 \%$. The hardening effect of lignin on bitumen and damage to fatigue performance could be reduced by increasing the oil content, the improvement was more obvious after aging. Moreover, the results of the relaxation test showed that the addition of lignin and the aging process increased the ratio of residual shear stress and relaxation time of the shear stress was reduced to a specific level. This was detrimental to relaxation performance, and the material was more prone to be damaged under repeated vehicle loads because the accumulated stress was not released and restored in time. The ratio and relaxation time of the lignin-bitumen with oil was even less than neat binder. The addition of oil signally decreased the ratio and relaxation time and improved relaxation performance. To obtain better low-intermediate temperature properties, $4 \%$ of bio-oil was recommended.

\section{REFERENCES}

ARAFAT, S., KUMAR, N., WASIUDDIN, N. M., OWHE, E. O. \& LYNAM, J. G. (2019) Sustainable lignin to enhance asphalt binder oxidative aging properties and mix properties. Journal of Cleaner Production, 217, 456-468.

BATISTA, K. B., PADILHA, R. P. L., CASTRO, T. O., SILVA, C. F. S. C., ARA JO, M. F. A. S., LEITE, L. F. M., PASA, V. M. D. \& LINS, V. F. C. (2018) High-temperature, lowtemperature and weathering aging performance of lignin modified asphalt binders. Industrial Crops and Products, 111, 107-116.

BRUIJNINCX, P. (2016) Lignin Valorisation: The Importance of a Full Value Chain Approach. Utrecht University.

JING, R. (2019) Ageing of bituminous materials: Experimental and numerical characterization. TU Delft Pavement Engineering. Delft University of Technology.

NORGBEY, E., HUANG, J., HIRSCH, V., LIU, W. J., WANG, M., RIPKE, O., LI, Y., TAKYI ANNAN, G. E., EWUSI-MENSAH, D., WANG, X., TREIB, G., RINK, A., NWANKWEGU, A. S., OPOKU, P. A. \& NKRUMAH, P. N. (2020) Unravelling the efficient use of waste lignin as a bitumen modifier for sustainable roads. Construction and Building Materials, 230, 116957.

SU, N., XIAO, F., WANG, J., CONG, L. \& AMIRKHANIAN, S. (2018) Productions and applications of bio-asphalts-A review. Construction and Building Materials, 183, 578591.

VAN VLIET, D., SLAGHEK, T., GIEZEN, C. \& HAAKSMAN, I. (2016) Lignin as a green alternative for bitumen.

XU, G., WANG, H. \& ZHU, H. (2017) Rheological properties and anti-aging performance of asphalt binder modified with wood lignin. Construction and Building Materials, 151, 801-808.

ZHANG, Y., LIU, X., APOSTOLIDIS, P., GARD, W., VAN DE VEN, M., ERKENS, S. \& JING, R. (2019) Chemical and Rheological Evaluation of Aged Lignin-Modified Bitumen. Materials, 12, 4176.

ZHANG, Y., LIU, X., APOSTOLIDIS, P., JING, R., ERKENS, S., POERAN, N. \& SKARPAS, A. (2020) Evaluation of Organosolv Lignin as an Oxidation Inhibitor in Bitumen. Molecules, 25. 